\title{
Regional environmental safety assessment
}

\author{
Elena Ganebnykh ${ }^{1, *}$, Tatyana Burtseva ${ }^{1,2}$, Anastasia Petuhova $^{1}$ and Angela Mottaeva ${ }^{3,4}$ \\ ${ }^{1}$ Vyatka State University, Moskovskaya str., 36, 610000, Kirov, Russia \\ ${ }^{2}$ Moscow University S.Yu. Witte, 2nd Kozhukhovsky passage, 12, 115432, Moscow, Russia \\ ${ }^{3}$ Moscow State University of Civil Engineering, 26, Yaroslavskoe Shosse, 129337, Moscow, Russia \\ ${ }^{4}$ Moscow Region State University, Radio str, 10A, 105005, Moscow, Russia
}

\begin{abstract}
The article provides a comparative analysis of the regions of the Volga Federal District, Russia to identify the dependence of industrial development on the environment. The research collected statistical information for all regions of the district and used it as a basis for constructing a perception map showing the actual regional situations compared to the "ideal point".
\end{abstract}

\section{Introduction}

Analyzing the research on methods of environmental safety assessment, the authors' positions may be group according to two main concepts: technology-related and biosphere. A technology-related concept presupposes the solution of environmental problems through assessment of environmental pollution, regulation of allowable pollution for different environments, creating waste treatment systems and resource-saving technologies. The biosphere concept is an empirical generalization of all accumulated experimental material on the basis of known laws of physics and biology [1]. The biosphere concept is aimed at determining the area of stability of any ecosystem. Within the framework of these concepts, there are many methods for assessing environmental safety.

Important challenges for the Russian economy in the very near future are moving away from the raw materials export model, radical greening, a sharp increase in the efficient use of huge natural potential, reducing the burden on the environment. The Russian Federation has vast territories that differ significantly both in climatic conditions and in the level of socio-economic development. It is clear that the more industrialized regions of the country are facing greater environmental problems. At the same time, modern environmental management systems [2] allow not only to maintain the current level of the regional ecology, but also to ensure its sustainable development.

In this regard, it is interesting to study the relationship between the level of industrial development and environmental safety in modern Russian realities [3]. The object of the study was the Volga Federal district, as it includes both industrialized regions and regions backward in industrial development.

\footnotetext{
${ }^{*}$ Corresponding author: ganebnykh@mail.ru
} 


\section{Methods and Results}

The purposes of comparative research demanded the analysis of regional environmental status and constructing a comparative perception map reflecting the positioning of the studied objects [4].

To solve the problem of positioning and assessing the ecological state of the regions, research visualization in the perception map system, we use the procedure of multidimensional scaling.

The perception map of 14 regions of the Volga Federal District using the procedure of factor analysis to determine the axes of the map in Minitab 14 program will allow to assess the regional environmental conditions on the basis of the analysis of a number of indicators. Initial data were assessment of the environmental condition of the regions of the Volga Federal District.

The main stages of the objects' positioning:

1. The problem of multidimensional scaling is formulated, which includes specifying goals, choosing objects for the analysis, in our case 14 regions of the Volga Federal District are to be analyzed. There should be at least 8 objects for high-quality positioning [5]. In our case, we analyze positions of 14 regions of the Volga Federal District on the basis of an assessment of 6 indicators within the period 2015-2017 (table 1).

Table 1. Key indicators for determining regional environmental status.

\begin{tabular}{|c|l|}
\hline Symbol & \multicolumn{1}{|c|}{ Indicator } \\
\hline $\mathrm{X}_{1}$ & Unauthorized disposal of solid waste, quantity \\
\hline $\mathrm{X}_{2}$ & Forest reproduction (\% young growth in total age forest structure) \\
\hline $\mathrm{X}_{3}$ & Assessment of water quality by households, \% of assessments "good quality" \\
\hline $\mathrm{X}_{4}$ & Stability of river flow resources, thousand. $\mathrm{m}^{3} /$ person., per year \\
\hline $\mathrm{X}_{5}$ & Emissions of air pollutants from stationary sources, total, ths. $\mathrm{t}$ \\
\hline $\mathrm{X}_{6}$ & $\begin{array}{l}\text { Specific indicator of pollutants emission into the atmosphere per unit area, } \mathrm{t} / \mathrm{km}^{2} \text { per } \\
\text { year }\end{array}$ \\
\hline
\end{tabular}

2. Statistical information was collected on the environmental situation in all regions of the district. Information collection took place in the desk mode.

The Kirov region is one of the regions of the Volga Federal District. The state of atmospheric air places the region in the 6th position in the district. The main sources of chemical air pollution in large cities of the Kirov region are motor transport and industrial enterprises. The largest part of pollutant emissions into the air comes from enterprises producing and distributing electricity, gas and water $(40.1 \%)$. The contribution of manufacturing facilities is $29.6 \%$; enterprises providing "other public, social and personal services" $-10.3 \%$. The study of atmospheric air in the settlements of the Kirov region revealed that the proportion of unsatisfactory research results in the region is lower than on the whole in the Russian Federation.

The gross emission of pollutants into the atmosphere from regional stationary sources in 2016 amounted to 98.6 thousand tons. Most emissions from stationary sources in the Kirov region $(78.0 \%$ ) are non-specific (industrial) emissions (carbon monoxide, sulfur dioxide, nitrogen oxides, suspended solids). The summary of pollutant emissions over the years is presented in table 2 . 
Table 2. Composition of the total mass of pollutants emissions from stationary sources in the Kirov region, thousand tons.

\begin{tabular}{|l|c|c|c|c|c|}
\hline & 2012 & 2013 & 2014 & 2015 & 2016 \\
\hline Total pollutant emissions & 101.3 & 103.3 & 114.9 & 96.1 & 98.6 \\
\hline solid & 20.3 & 20.0 & 22.1 & 17.9 & 16.8 \\
\hline gases & 81.0 & 83.3 & 92.8 & 78.2 & 81.8 \\
\hline among them: & & & & & \\
\hline sulfur dioxide & 14.8 & 14.1 & 14.9 & 10.8 & 7.8 \\
\hline carbon oxide & 29.1 & 28.9 & 35.2 & 34.1 & 39.9 \\
\hline nitrogen oxides & 13.9 & 13.7 & 13.9 & 12.1 & 11.8 \\
\hline hydrocarbons & 14.3 & 19.0 & 21.5 & 15.0 & 16.6 \\
\hline volatile organic compounds & 6.4 & 5.3 & 4.9 & 4.0 & 5.7 \\
\hline
\end{tabular}

There are 19753 watercourses with a total length of 66.6 thousand $\mathrm{km}$ on the territory of the Kirov region, $94.6 \%$ of them are from the category of small watercourses up to $10 \mathrm{~km}$. Average density of the regional river network is $0.55 \mathrm{~km} / \mathrm{km}^{2}$. One of the main indicators of surface water quality is the value of dissolved oxygen. Oxygen should be present in water in sufficient quantity (not less than 4-6 $\mathrm{mgO}_{2} / \mathrm{dm}^{3}$ ), providing conditions for hydrobionts' breathing. It is also necessary for self-purification of water bodies, as it is involved in oxidizing organic and other impurities, decomposition of dead organisms. The oxygen regime of reservoirs in 2016 was satisfactory, average annual content of dissolved oxygen in surface waters was $8.95 \mathrm{mg} \mathrm{O}_{2} / \mathrm{dm}^{3}$.

The state of water objects in places of population water management, used as a drinking water supply (category 1), in 2016 have improved: the proportion of water samples not meeting sanitary requirements on sanitary-chemical indicators has decreased from $57.6 \%$ in 2009 to $43.7 \%$ in 2016 (in 2015 - $45.2 \%$ ); microbiological indicators - from $34.0 \%$ in 2009 to $27.0 \%$ in 2016 (in $2015-24.1 \%$ ). The share of water samples from the 1 st category reservoirs that do not meet sanitary requirements on parasitological indicators was $0 \%$ in $2016(2014-1.8 \%, 2015-2.8 \%)$. The reason for the low water quality of surface water bodies for many years has been discharge of insufficiently treated wastewater, as well as free water removal from the territories of settlements due to the lack of storm water sewers. As a result of unsatisfactory work of waste treatment facilities eggs of helminths are still found in reservoir water in sewage discharge places. In total, there are 185 wastewater treatment facilities of mechanical and biological treatment in the region. Many wastewater treatment plants operate technological equipment with a high degree of wear and tear, use outdated schemes of sewage treatment that do not provide the proper degree of purification.

Over the past 5 years in the region witnessed a tendency to reduce the total volume of wastewater discharge into surface water bodies from 186.7 million $\mathrm{m}^{3}$ in 2012 to 129.1 million $\mathrm{m}^{3}$ in 2016 . About $91 \%$ of wastewater is discharged into surface water bodies in the region. This is mainly the category of "insufficiently treated wastewater at waste treatment facilities" (69.3\%). The volume of wastewater of the category "contaminated without treatment" is about $29.3 \%$, the category "normatively treated" is $1.4 \%$ of the total volume of wastewater discharged in 2016 into surface water bodies. In terms of quality of water bodies, the region is among the three best ones in the Volga Federal District. The annual trend to reduce water consumption and sanitation is up to $7 \%$.

One of the most urgent and at the same time problematic areas of environmental safety in the region is waste management. The number of waste disposal facilities that meet legal requirements ranks the region the $3 \mathrm{rd}$ in the Volga Federal District. 
Currently, the volume of waste accumulated and disposed at the disposal facilities is over 81 million tons. In addition, more than 41 million tons of production and consumption waste are placed at temporary and long-term storage facilities (ash dumps, sludge storage, storage, open and closed temporary storage sites). According to the Federal Service for Supervision of Consumer Rights Protection and Human Welfare of the Kirov region, 18 landfills are operated with a filling factor of 50 to $90 \%$.

Annually formed waste products replenish the existing waste disposal facilities. The increase in volume of various types of waste depends not only on the technological level of production processes, but also on the level of waste management culture, as well as on the technical equipment of enterprises and organizations engaged in waste management. The largest percentage in the mass of waste formed in 2016 is taken by: cattle manure, scrap and waste containing uncontaminated ferrous metals in the form of unsorted products, pieces, harmless ash-slag mixture from coal combustion, wood waste

For a long time waste production of enterprises of the energy complex and chemical industry have not been used and involved in the market turnover for a number of reasons, issues on the use ash and slag CHP, wood waste by regional enterprises remain unresolved. Currently, there is practically no processing of individual components of solid waste into raw materials for recycling: the volume of recycled waste of polymeric materials, paper, etc.is extremely small, and there are no production facilities for processing waste glass. Insufficient development of waste recycling is due to the lack of appropriate infrastructure and economic incentives for economic entities.

The ecological state of other regions of the Volga Federal District was analyzed similarly. The comparative characteristic of regions is more clearly expressed by means of the perception map.

3. The generalized results on the basis of the desk study of the objects analyzed are presented in Table 3. Next, these indicators are transferred into the scoring system to be compared. The "ideal point" object is included in the analysis. An ideal object is an object that the consumer would prefer to all others, including objects that can be shown in space, but does not actually exist [5]. This is a combination of the preferred consumer levels of all attributes. One of the viable reasons to apply ideal objects on the map is that they allow to identify segments of consumers, whose ideal objects are similar.

Table 3. Initial data for the perception map.

\begin{tabular}{|l|r|c|c|c|c|c|c|c|c|c|c|c|}
\hline \multirow{2}{*}{ Region } & \multicolumn{2}{|c|}{$\mathbf{X}_{\mathbf{1}}$} & \multicolumn{2}{c|}{$\mathbf{X}_{\mathbf{2}}$} & \multicolumn{2}{c|}{$\mathbf{X}_{\mathbf{3}}$} & \multicolumn{2}{c|}{$\mathbf{X}_{\mathbf{4}}$} & \multicolumn{2}{c|}{$\mathbf{X}_{\mathbf{5}}$} & \multicolumn{3}{c|}{$\mathbf{X}_{\mathbf{6}}$} \\
\cline { 2 - 14 } & fact & score & fact & score & fact & score & fact & score & fact & score & fact & score \\
\hline Bashkortostan & 3028 & 0.86 & 17.7 & 2.70 & 33.4 & 7.89 & 8.87 & 0.56 & 706.6 & 1.20 & 4.94 & 3.44 \\
\hline Mari El & 1130 & 2.32 & 46.4 & 7.07 & 34.7 & 8.20 & 114.75 & 7.24 & 84.9 & 10.0 & 3.63 & 4.68 \\
\hline Mordovia & 263 & 10.00 & 35.4 & 5.40 & 29.8 & 7.04 & 4.71 & 0.29 & 108.1 & 7.85 & 4.14 & 4.10 \\
\hline Tatarstan & 440 & 5.97 & 21.9 & 3.34 & 30.6 & 7.23 & 55.37 & 3.49 & 569.4 & 1.49 & 8.39 & 2.02 \\
\hline Udmurtia & 293 & 8.97 & 32.1 & 4.89 & 28.0 & 6.62 & 54.38 & 3.44 & 284.3 & 2.98 & 6.76 & 2.07 \\
\hline Chuvashia & 2246 & 1.17 & 50.0 & 7.62 & 41.9 & 9.91 & 64.37 & 4.07 & 110.7 & 7.67 & 6.03 & 2.82 \\
\hline Perm & 2894 & 0.90 & 35.6 & 5.43 & 25.9 & 6.12 & 27.37 & 1.73 & 558.5 & 1.52 & 3.49 & 4.87 \\
\hline Kirov & 755 & 3.48 & 31.3 & 4.77 & 29.9 & 7.06 & 39.62 & 2.50 & 204.4 & 4.15 & 1.70 & 10.0 \\
\hline
\end{tabular}




\begin{tabular}{|l|r|r|r|r|r|r|r|r|r|r|r|r|}
\hline $\begin{array}{l}\text { Nizhny } \\
\text { Novgorod }\end{array}$ & 2672 & 0.98 & 45.3 & 6.91 & 25.7 & 6.07 & 22.54 & 1.42 & 427.6 & 1.98 & 5.58 & 3.04 \\
\hline Orenburg & 1043 & 2.50 & 21.2 & 3.23 & 42.6 & 10.0 & 3.16 & 0.20 & 947.5 & 0.89 & 7.66 & 2.22 \\
\hline Penza & 1106 & 2.37 & 21.6 & 3.29 & 32.5 & 7.68 & 3.48 & 0.22 & 109.5 & 7.75 & 2.53 & 6.72 \\
\hline Samara & 447 & 5.88 & 25.0 & 3.81 & 14.0 & 3.30 & 62.91 & 3.97 & 565.5 & 1.50 & 10.56 & 1.61 \\
\hline Saratov & 606 & 4.34 & 65.6 & 10.0 & 14.2 & 2.97 & 82.25 & 5.20 & 360.4 & 2.36 & 3.56 & 4.77 \\
\hline Ulyanovsk & 2726 & 0.96 & 30.0 & 4.57 & 25.3 & 6.03 & 158.31 & 10.0 & 135.1 & 6.28 & 3.63 & 4.68 \\
\hline Ideal point & - & 10 & - & 10 & - & 10 & - & 10 & - & 10 & - & 10 \\
\hline
\end{tabular}

4. To name the axes of the perception map, it is necessary to determine the factor loads of each indicator with directions, to determine which factors correlate strongly with which indicators, which will determine the axes of the map. This procedure was performed using Minitab 16 statistical analysis software. Factor loads, on the basis of which the factors are interpreted, are presented in table 4.

Table 2. Naming the axes of the perception map.

\begin{tabular}{|c|l|c|c|}
\hline \# & \multicolumn{1}{|c|}{ Assessment index } & $\begin{array}{c}\text { Axe 1: } \\
\text { «Forest reproduction } \\
\text { and stability of river } \\
\text { flow resources» }\end{array}$ & $\begin{array}{c}\text { Axe 2: } \\
\text { «Water quality and } \\
\text { air pollution» }\end{array}$ \\
\hline $\mathrm{X} 1$ & Unauthorized disposal of solid waste, quantity & 0.482 & -0.016 \\
\hline $\mathrm{X} 2$ & $\begin{array}{l}\text { Forest reproduction (\% young growth in total } \\
\text { age forest structure) }\end{array}$ & 0.816 & 0.133 \\
\hline $\mathrm{X} 3$ & $\begin{array}{l}\text { Assessment of water quality by } \\
\text { households, \% of assessments "good } \\
\text { quality" }\end{array}$ & -0.263 & 0.877 \\
\hline $\mathrm{X} 4$ & $\begin{array}{l}\text { Stability of river flow resources, thousand. } \\
\text { m/person., per year }\end{array}$ & 0.783 & 0.169 \\
\hline $\mathrm{X} 5$ & $\begin{array}{l}\text { Emissions of air pollutants from } \\
\text { stationary sources, total, ths. } \mathrm{t}\end{array}$ & 0.494 & 0.739 \\
\hline $\mathrm{X} 6$ & $\begin{array}{l}\text { Specific indicator of pollutants emission } \\
\text { into the atmosphere per unit area, } \mathrm{t} / \mathrm{km}^{2} \\
\text { per year }\end{array}$ & 0.436 & 0.537 \\
\hline
\end{tabular}

5. Analyzing the factors model, we conclude that a relatively high correlation value for factor 1 is observed between variables $\mathrm{x}_{2}$ (forest reproduction (\% of young growth in the total forest age structure) and $\mathrm{x}_{2}$ (availability of river flow resources, thousand $\mathrm{m}^{3} /$ person, per year), so this factor (axis 1) can be called "Forest reproduction and stability of river flow resources". Factor 2 correlates with variables $\mathrm{X}_{3}$ (assessment of water quality by households, \% assessments "good quality"), $\mathrm{X}_{5}$ (emissions of air pollutants from stationary sources, total, ths. $t$ ) and $\mathrm{X}_{6}$ (specific indicator of pollutants emission into the atmosphere per unit area, $\mathrm{t} / \mathrm{km}^{2}$ per year), so this factor (axis 2) can be called "Water quality and air pollution".

6. The interpretation of the research results is based on the assessment of the location of objects relative to each other and to the position of the ideal point. The objects located nearby are the most similar by assessments. As you can see, these are regions such as the Chuvash Republic, the Penza, Kirov and Orenburg regions, as well as the next group of 
regions - the Perm region, the Republic of Tatarstan and the Nizhny Novgorod region. Isolated objects differ from other regions more either for the better or, conversely, have the lowest scores.

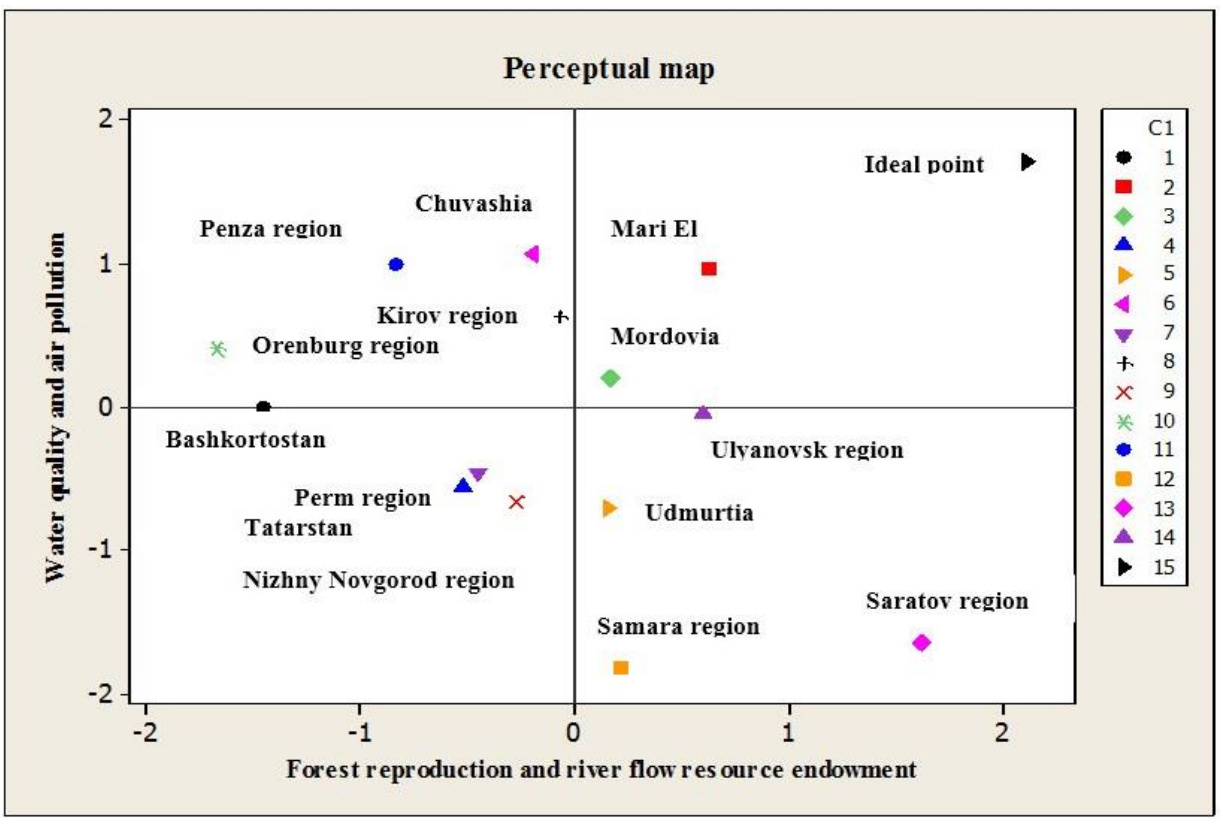

Fig. 1. Perception of the environmental state of regions of the Volga Federal District.

Objects that are far from the beginning of the axes are stronger in this characteristic. As it can be seen, the Republic of Mari El has a strong position both in relation to the axis of "Forest Reproduction and stubility of river flow resources" and in relation to axis 2 "Water quality and air pollution". The position of the Republic of Mordovia is also close to the ideal point.

The Chuvash Republic, the Penza and Kirov region have sufficiently strong position from the point of view of water quality assessment and the specific rate of pollutant emissions into the atmosphere, but on the other hand they are poorly evaluated from the point of view of indicators "Stability of river flow, thousand $\mathrm{m}^{3} /$ person per year" and "Forest reproduction". Such regions as the Republic of Bashkortostan, the Perm, Nizhny Novgorod region and the Republic of Tatarstan have the weakest positions in relation to the axes of the perception map. The positions of these research objects require purposeful work in terms of the formation of environmental safety of the region [6,7].

Thus, the construction of a perception map makes it possible to visualize the position of the objects of analysis, can be used to obtain a spatial representation of the perception of the environmental assessment of regions. Also, on the basis of the map it is possible to conduct a comparative analysis in the dynamics for several periods, assessing the situation of the regions before and after the implementing measures aimed at improving the regional environmental condition.

\section{Conclusion}

The analysis showed that at the moment there is a direct relationship between the level of industrial development in the region (the number of industrial enterprises) and the state of the environment. As the existing technologies allow to carry out all types of industrial 
activity taking into account sustainable ecological development of environment, it means that enterprises do not use the existing technologies.

The analysis by showed that the introduction of "green" technologies is moving along the path of forced measures. The development of the environmental management system requires a strong regulatory framework, which the Russian Federation lacks at present.

\section{References}

1. J. Lubchenco, A. Olson, Ecology 72(2), 371-412 (1991)

2. A. Marouen, International Journal of Business and Management 10(11), 107-121 (2015)

3. S.A. Melnyk, R. Sroufe, R.J. Calantone, Journal of Operations Management 21, 329351 (2003)

4. O. Soboleva, T. Burtseva, E. Barmina, E. Ganebnykh, P. Tokareva, Overcoming uncertainty of institutional environment as a tool of global crisis management (Springer, Contribution to Economics, 2017)

5. I. Markina, A. Sharkova, M. Barna, International Journal of Entrepreneurship 22(3), 12-19 (2018)

6. D. Aaker, Kumar, V. R.Leone, G. Day, Marketing research (Wiley, 2012) 